\title{
Feasibility of Reuse of Effluent from the Extended Aeration Process of Wastewater Treatment Plant in the Bojnoord City for Agricultural and Irrigation Uses
}

\author{
Tayebeh Hatami (MSc) ${ }^{1}$, Azam Nadali (MSc) ${ }^{1}$, Ghodratollah Roshanaei (PhD)², Reza \\ Shokoohi (PhD) $)^{1, *}$
}

${ }^{I}$ Department of Environmental Health, Faculty of Public Health, University of Medical Science, Hamadan, Iran

${ }^{2}$ Department of Biostatistics and Epidemiology, School of Public Health. Hamadan University of Medical Sciences, Hamadan, Iran

* Corresponding Author: Reza Shokoohi, Department of Environmental Health, Faculty of Public Health, University of Medical Science, Hamadan, Iran. Email: reza.shokohi@umsha.ac.ir

\begin{tabular}{|c|c|}
\hline & Abstract \\
\hline $\begin{array}{l}\text { Received: } 11 / 02 / 2017 \\
\text { Accepted: } 03 / 04 / 2018\end{array}$ & $\begin{array}{l}\text { Background and Objective: Due to increasing the water demand and the } \\
\text { lack of its resources, the reuse of effluents is considered as a useful option }\end{array}$ \\
\hline \multirow[t]{2}{*}{$\begin{array}{l}\text { How to Cite this Article: } \\
\text { Hatami T, Nadali A, Roshanaei } \\
\text { Gh, Shokoohi R. Feasibility of } \\
\text { Reuse of Effluent from the } \\
\text { Extended Aeration Process of } \\
\text { Wastewater Treatment Plant } \\
\text { in the Bojnoord City for } \\
\text { Agricultural and Irrigation Uses. } \\
\text { Pajouhan Scientific Journal. } \\
\begin{array}{l}\text { 2018; 16(3): 20-28. DOI: } \\
\text { 10.18869/psj.16.3.20 }\end{array}\end{array}$} & $\begin{array}{l}\text { the possibility of the reuse of effluents from the extended aeration process } \\
\text { in the wastewater treatment plant of the Bojnoord city for agricultural uses. } \\
\text { Materials and Methods: This is a descriptive-analytical study which } \\
\text { performed in } 2013 \text { on the quality of effluents in the wastewater treatment } \\
\text { plant of the Bojnoord city by measuring the parameters of Electrical } \\
\text { Conductivity (EC), Chemical Oxygen Demand (COD), Biological Oxygen } \\
\text { Demand (BOD), nitrogen, phosphorus, Total Suspended Solids (TSS), } \\
\text { Total Dissolved Solids (TDS), Sodium Adsorption Ratio (SAR), sodium } \\
\text { percentage, magnesium ions, potassium ions, calcium ions, sodium ions } \\
\text { and chloride. } \\
\text { Results: The results shown that, the removal efficacy of BOD and COD } \\
\text { were } 88 \% \text { and } 89 \% \text {, respectively, and it was higher than } 85 \text { percent for TSS } \\
\text { and VSS factors; thus, the average residual concentration of BOD, COD, } \\
\text { TSS and phosphate in the outflow were } 27 \text {, } 61 \text {, } 26 \text { and } 11.34 \text { mg, } \\
\text { respectively. The average values of pH and EC in treated effluent were } \\
\text { obtained } 7.45 \text { and } 1940 \mu \text { s/cm, respectively. Moreover, the values of } \\
\text { chloride and SAR for the effluent of the wastewater treatment plant of the } \\
\text { Bojnoord were achieved } 3.89 \text { meq/L and } 221 \text { mg/L, respectively. } \\
\text { Conclusion: based on the results, it can be concluded that the effluents of } \\
\text { the wastewater treatment plant of the Bojnoord city can be valuable for use } \\
\text { in agriculture; but, due to the high concentration of chloride in treated } \\
\text { effluent, it is recommended that this effluent used for semi-sensitive plants. } \\
\text { Furthermore, this effluent is not suitable for feeding to groundwater and for } \\
\text { discharging into the surface water and it is needed to advanced treatment } \\
\text { based on the standards. }\end{array}$ \\
\hline & $\begin{array}{l}\text { Keywords: Bojnoord; Extended Aeration; Municipal Wastewater Treatment; } \\
\text { Reuse }\end{array}$ \\
\hline
\end{tabular}


dof: $10.18869 / \mathrm{psj} .16 .3 .20$

امكانسنجى استفاده مجدد از يساب خروجى فر آيند هوادهى تسترده تصفيه فاضلاب شهر بجنورد جهت مصارف كشاورزى و آبيارى

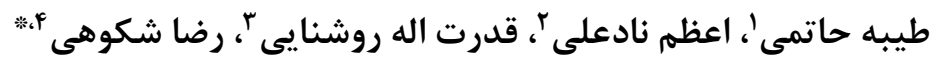 \\ ' كارشناسى ارشد مهندسى بهداشت محيط، دانشكده بهداشت، دانشعاه علوم يزشكى همدان، همدان، ايران

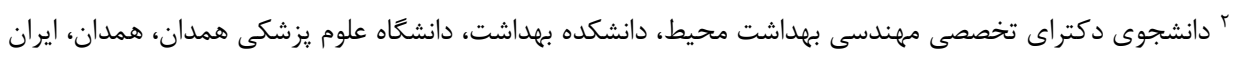

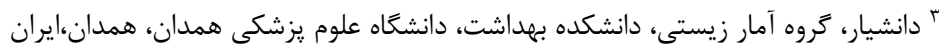

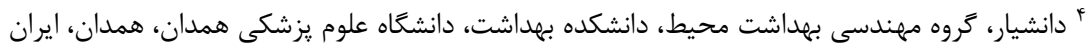

* نويسنده مسئول: رضا شكوهى، كروه مهندسى بهداشت محيط، دانشكده بهداشت، دانشكاه علوم يزشكى همدان، همدان، ايران.

reza.shokohi@umsha.ac.ir ايميل، نوهن مسئول:

\begin{tabular}{|c|c|}
\hline 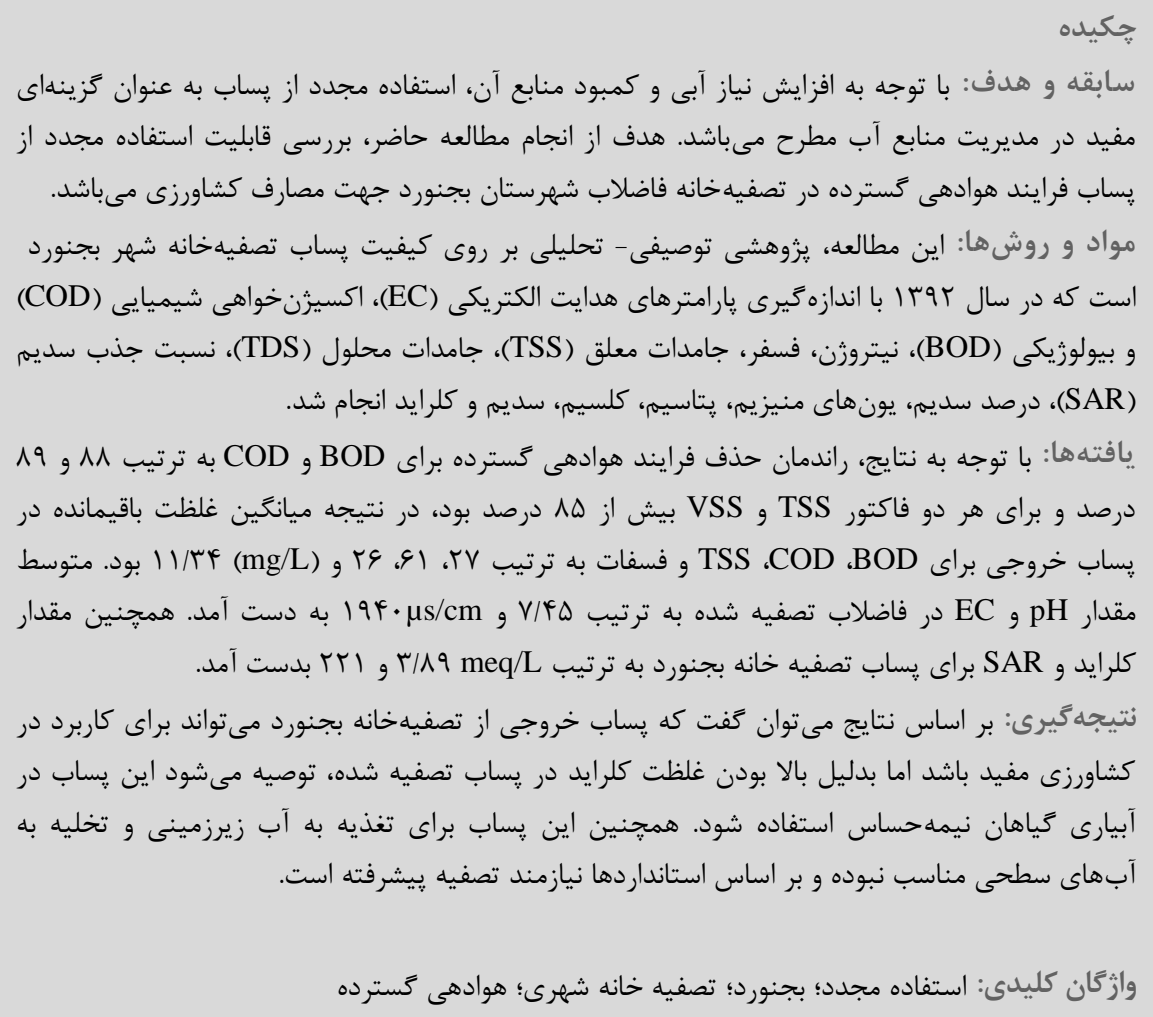 & 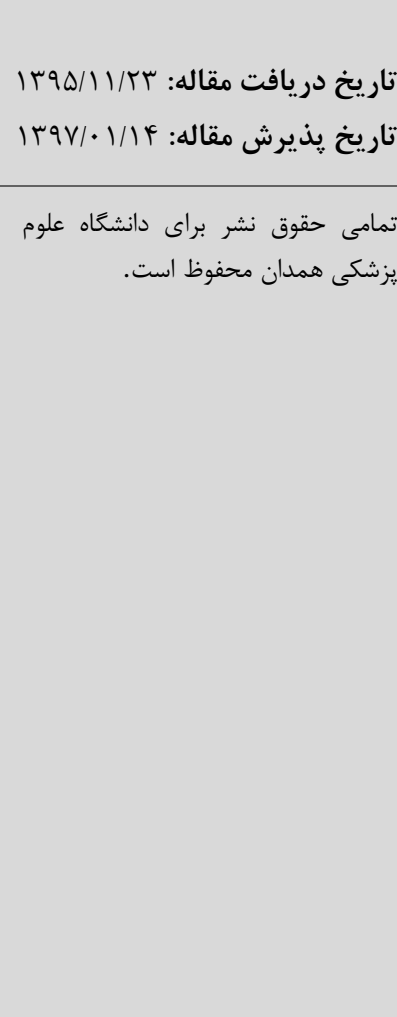 \\
\hline
\end{tabular}

مقلدمه

خانكى به دليل حجم زياد و كيفيت مناسب بعد از تصفيه، به

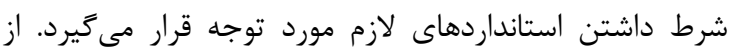

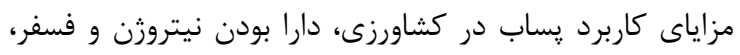

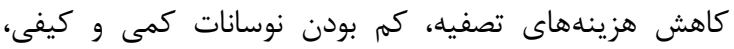

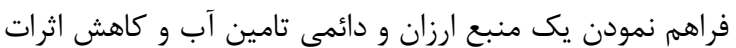

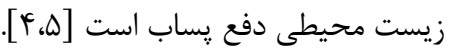

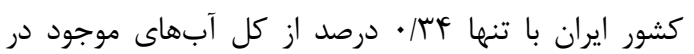

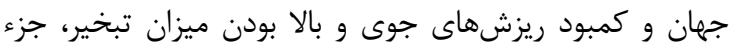

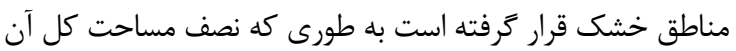

امروزه با صنعتى شدن جوامع و افزايش جمعيت، تقاضاى آب و به دنبال آن مقدار توليد فاضلاب افزايش يافته است. از

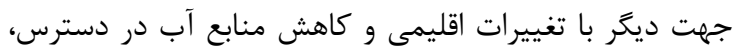

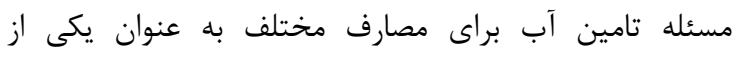

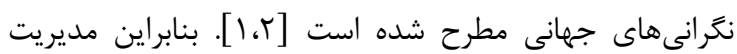

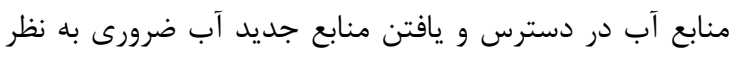

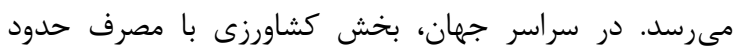

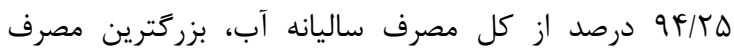
كننده آب است [ب]. از بين منابع مختلف رِّاب، فاضلاب 
واقع شده است و بر اساس اطلاعات هواشناسى موجود،

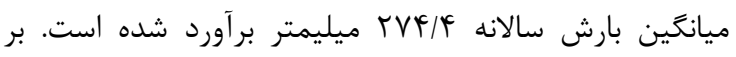

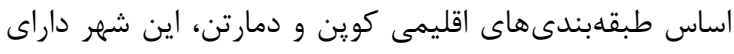

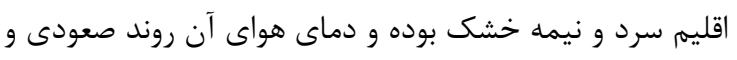

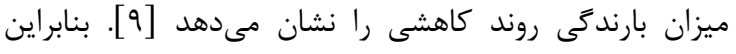

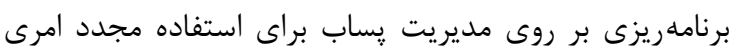

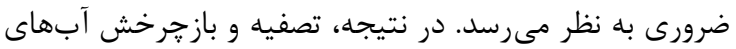

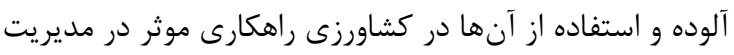

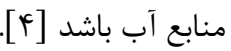

\section{استراتثى نمونه بردارى}

اين يزوهش از نوع توصيفى- تحليلى بوده و به مدت يكسال

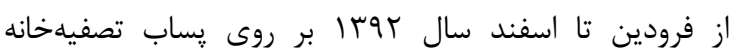

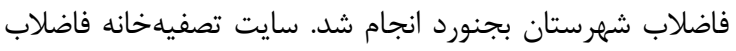

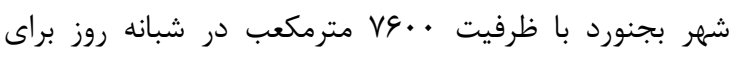
F.... بهرهبردارى مىشود. ترتيب و توالى واحدهاى مختلف تصفيهخانه

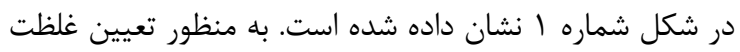

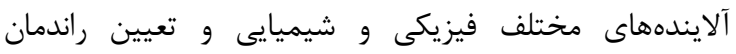
تصفيهخانه در حذف آلايندهها، نمونهبردارى از دو نقطه دئه در

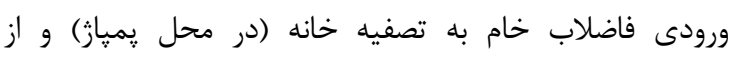

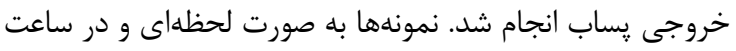

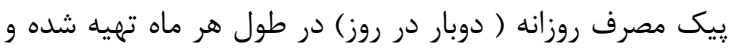

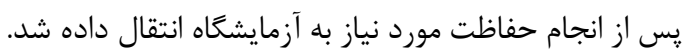

\section{آناليز نمونهها}

نمونهها، به منظور تعيين يارامترهاى COD (اكسيرن مورد نياز
را مناطق خشك و نيمه خشك تشكيل مىدهد [ع]. فاضلاب تصفيه شده شهرى يكى از در دسترس ترين منابع آبى جايكزين

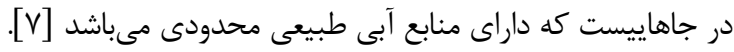

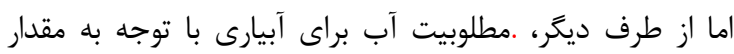

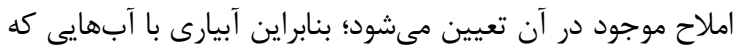

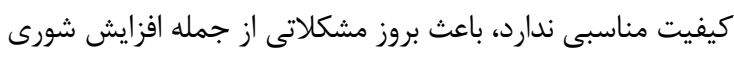

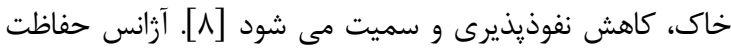

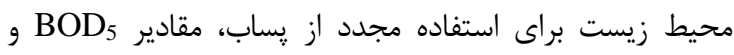
, COD

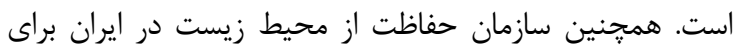

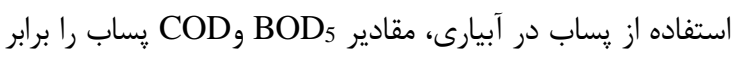

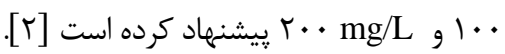
در صورت نياز به استفاده مجدد از يساب، بايد مشخص

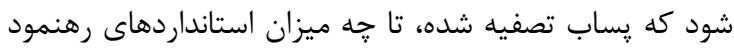

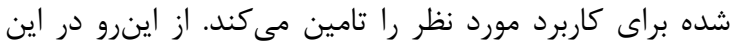

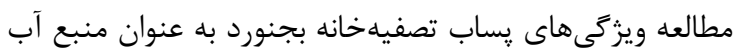

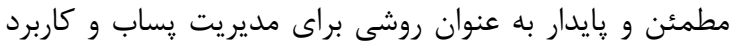

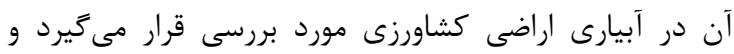

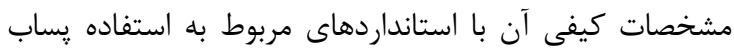

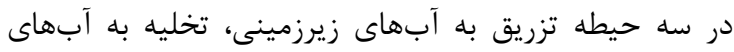
سطحى و كاربرد آن در كشاورزى مقايسه مى بـود.

\section{مواد و روشها محل مطالعه}

شهرستان بجنورد مركز استان خراسان شمالى با مساحت مداح

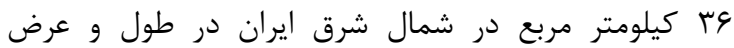

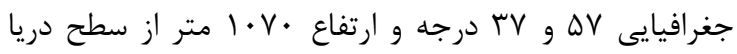

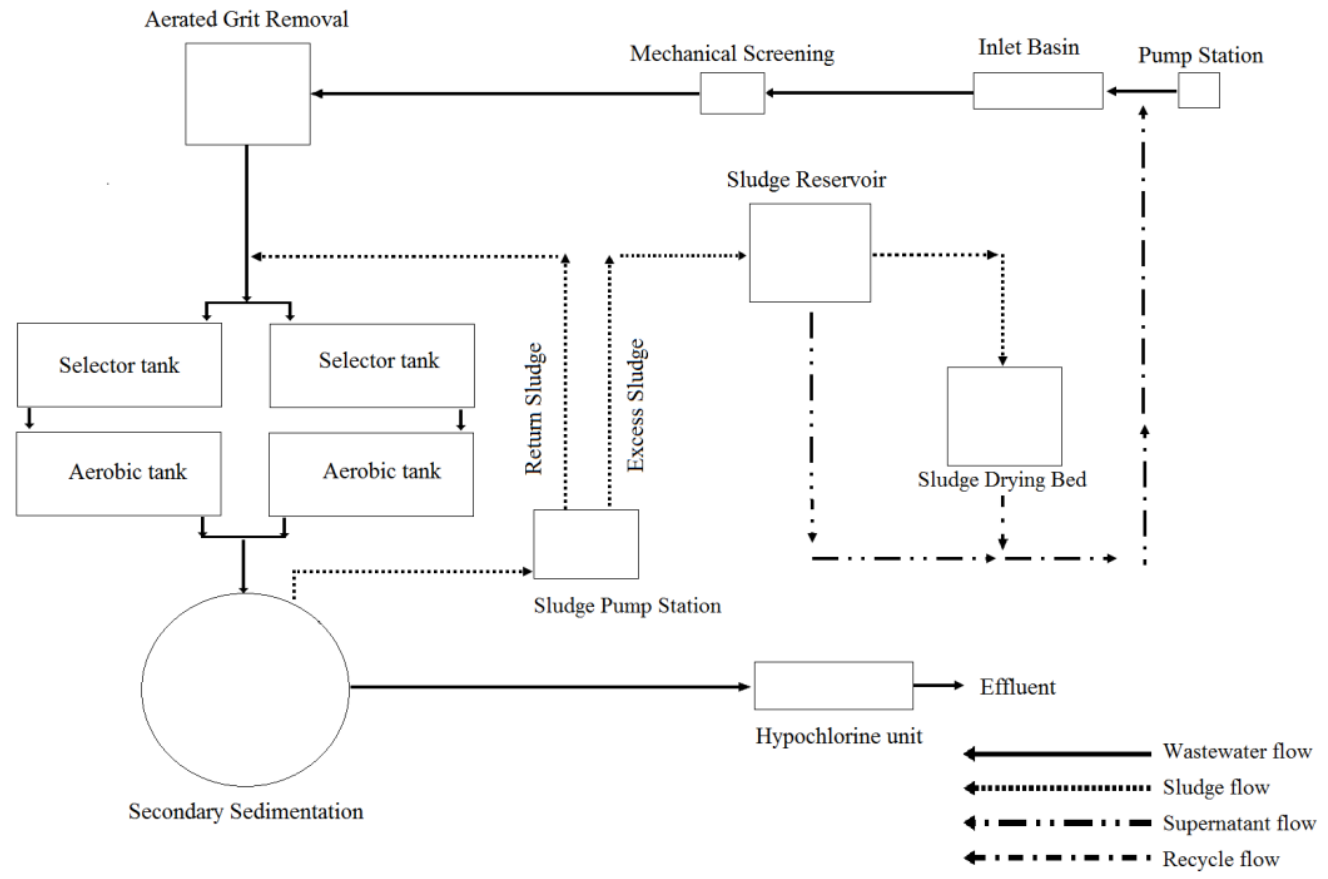

شكل (: دياكرام تصفيه خانه فاضلاب شهرستان بجنورد (فرايند هوادهى گسترده) 
$\mathrm{SAR}=\frac{\left[\mathrm{Na}^{+}\right]}{\sqrt{\frac{\mathrm{Ca}^{2+}+\mathrm{Mg}^{2+}}{2}}}$

$\% \mathrm{Na}=\frac{100 \mathrm{Na}}{\mathrm{Ca}+\mathrm{Mg}+\mathrm{Na}+\mathrm{K}}$

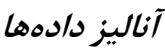

جهت آناليز دادهها و رسم نمودارها از نرم افزار SPSS 16.0

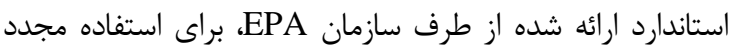

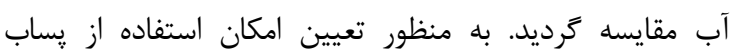

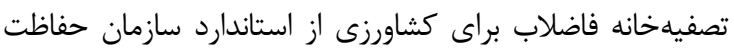
محيط زيست ايران، رهنمود WHO و رهنمود FAO استفاده شد.
شيميايى)، BOD (اكسيرن مورد نياز بيولوزيكى)، TN (نيتروزن

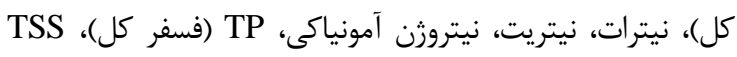
(جامدات معلق كل)، TDS (جامدات محلول كل)، كلسيم، منيزيم،

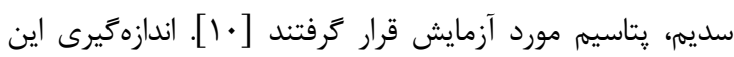

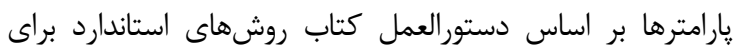

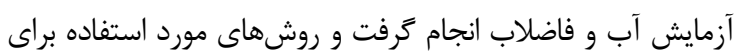

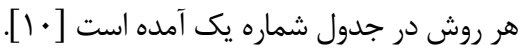

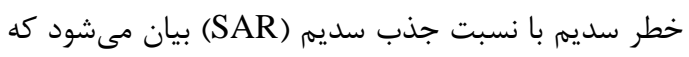

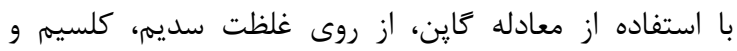

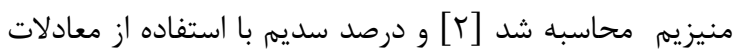

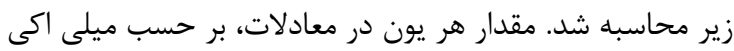

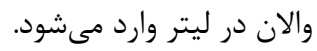

جدول ا: روش اندازهگيرى يارامترهاى مورد سنجش جهت ارزيابى كارايى تصفيه خانه [•l]

\begin{tabular}{|c|c|c|c|}
\hline شماره روش & ابزار و روش & واحد & يار امترها \\
\hline- & pH متر (روش يتانسيومترى) & - & $\mathrm{pH}$ \\
\hline- & 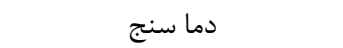 & ${ }^{0} \mathrm{C}$ & دما \\
\hline$\Delta T r \cdot C$ & تقطير برگشتى (تيتراسيون) & $(\mathrm{mg} / \mathrm{l})$ & COD \\
\hline$\Delta T I \cdot B$ & روش اصلاح شده وينكلر آزايد & $(\mathrm{mg} / \mathrm{l})$ & BOD \\
\hline$r \Delta F \cdot D$ & وزن سنجى & $(\mathrm{mg} / \mathrm{l})$ & TSS \\
\hline$r \Delta F \cdot E$ & وزن سنجى & $(\mathrm{mg} / \mathrm{l})$ & VSS \\
\hline Fa..PC. & رنگ سنجى & $(\mathrm{mg} / \mathrm{l})$ & 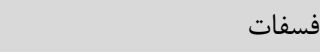 \\
\hline$\Delta \Delta F \cdot C$ & MBAS & $(\mathrm{mg} / \mathrm{l})$ & سورفاكتانت آنيونى (دترجنت) \\
\hline $\mathrm{F} \Delta \cdots-\mathrm{NO}_{3}^{-} \mathrm{B}$ & رنح سنجى (اسيكتروفتومترى) & $(\mathrm{mg} / \mathrm{l})$ & 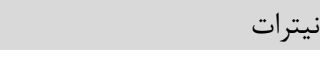 \\
\hline $\mathrm{F} \omega \cdots \mathrm{NO}_{2}^{-} \mathrm{B}$ & رنى سنجى & $(\mathrm{mg} / \mathrm{l})$ & نيتريت \\
\hline$r \Delta \cdots-\mathrm{Na} B$. & فليم فتومتر & $(\mathrm{mg} / \mathrm{l})$ & 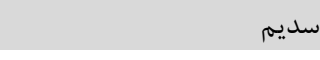 \\
\hline$r \omega \cdots-K B$. & فليم فتومتر & $(\mathrm{mg} / \mathrm{l})$ & 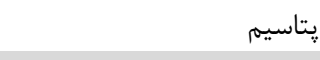 \\
\hline$\uparrow \Delta \cdots-N_{\text {org }} B$ & روش كجلدال & $(\mathrm{mg} / \mathrm{l})$ & نيتروزن كل \\
\hline
\end{tabular}

يافتهها

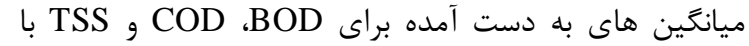

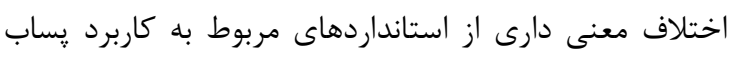

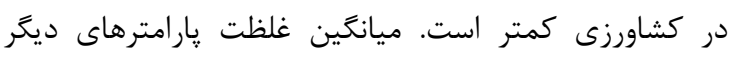

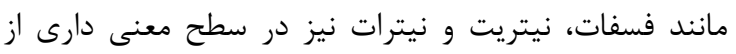

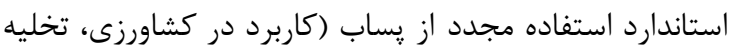

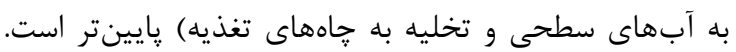

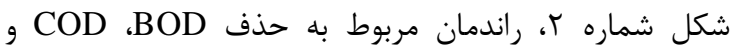

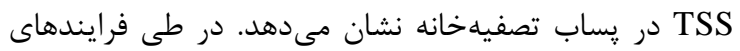

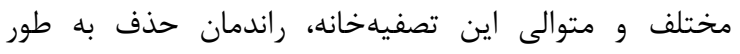

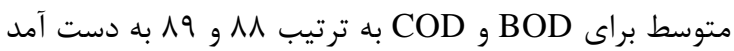
كه راندمان حذف BOD در فصل تابستان بيش از فصول ديكر

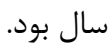
جدول شماره ؟ نتايج آناليز ANOVA را براى خصوصيات

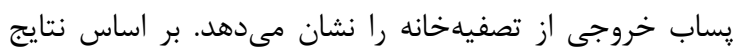

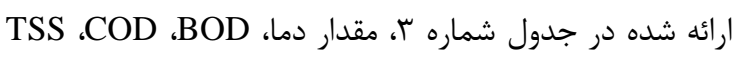

به منظور انتخاب تزينه مناسب جهت مصرف مجدد

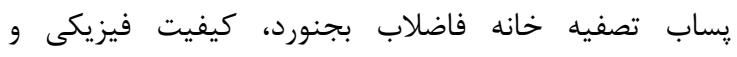

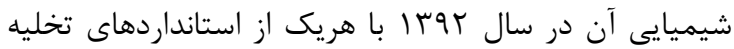

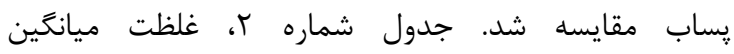

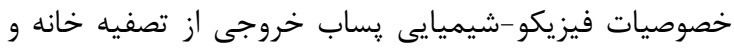

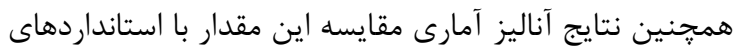

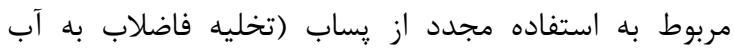

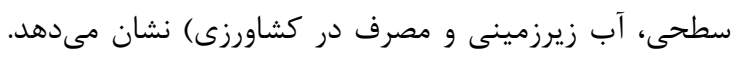

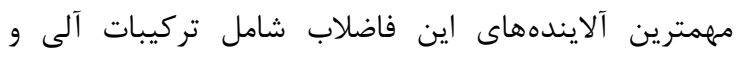

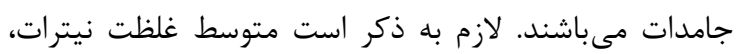

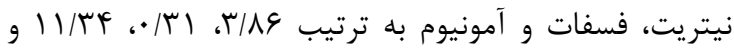
pH ميلى F/V9

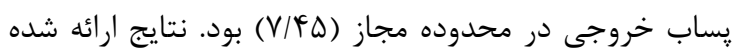

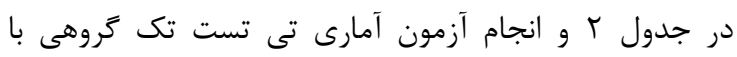

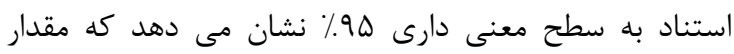


جدول r: مقايسه خصوصيات مختلف يساب تصفيه خانه بجنورد با استانداردهاى مربوط به كاربرد مجدد يساب (one sample T-Test)

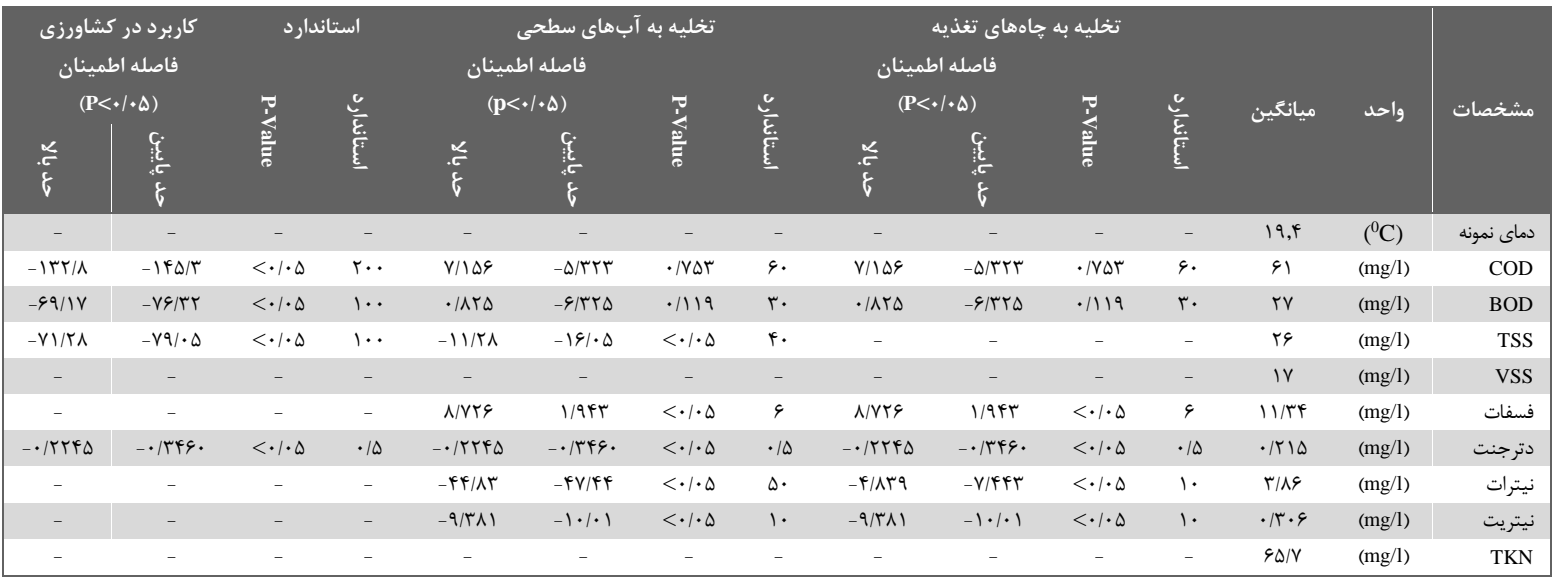

$$
\text { راندمان حذف (.) }
$$

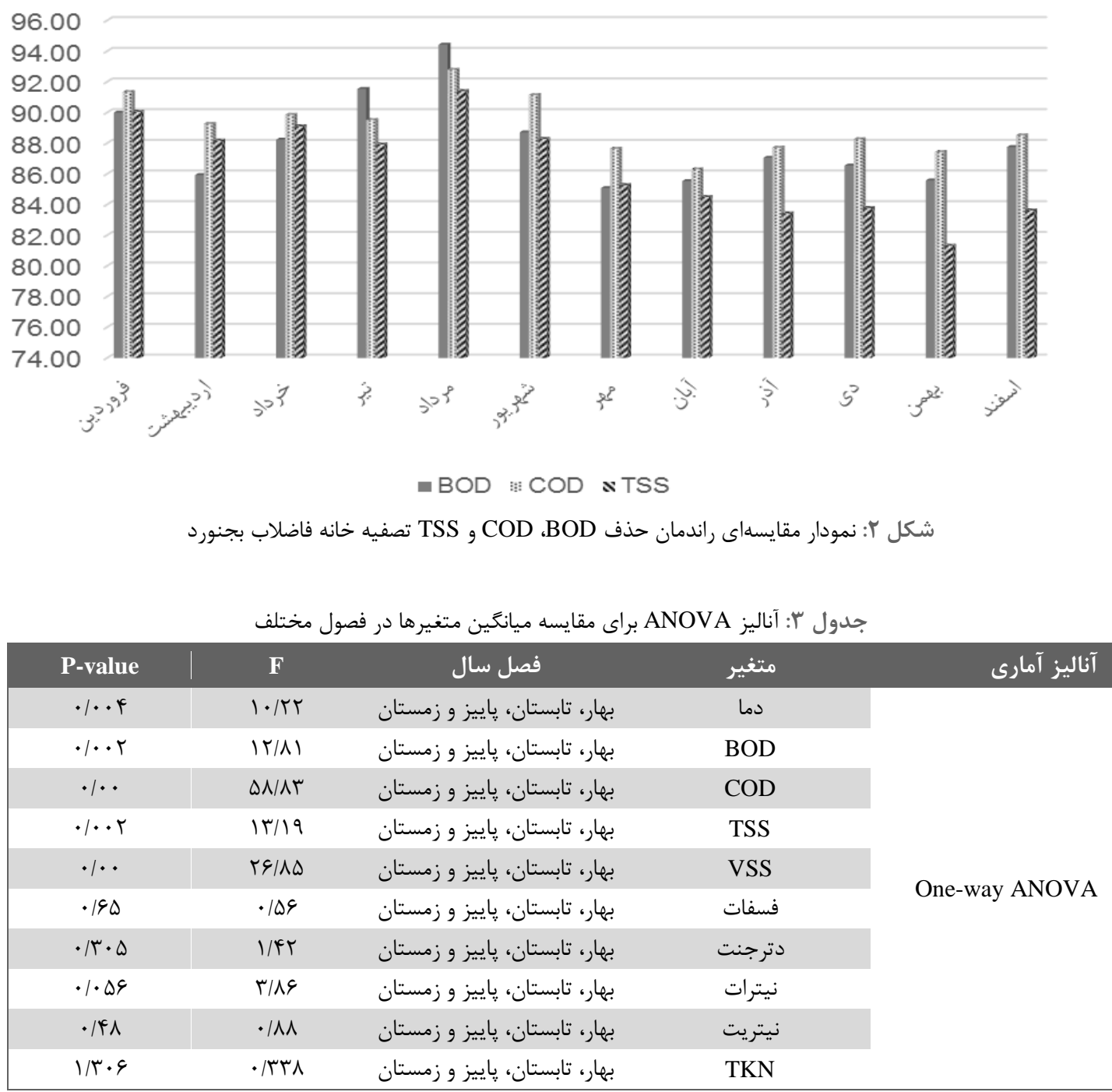

نتايج اندازهيرى فاكتورهاى كيفى فاضلاب شامل غلظت

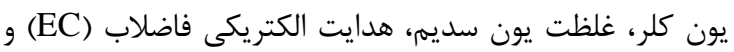
نسبت جذب سديم (SAR) و مقايسه آن بان استانداردهاى مداى

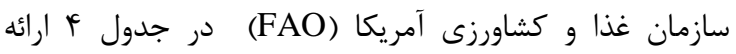

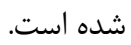

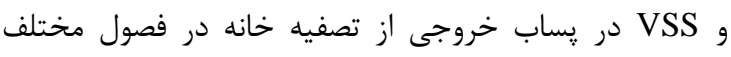
متفاوت است كه اين تفاوت از نظر آمارى معنى دار است. نتايج

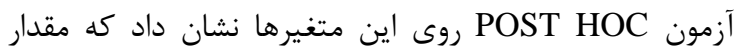

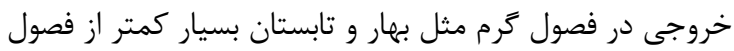
ياييز و زمستان است. 


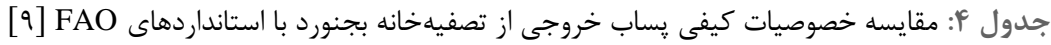

\begin{tabular}{|c|c|c|c|c|c|c|}
\hline 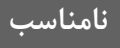 & مورد ترديد & قابل قبول & خوب ل & عالى ل & بساب تصفيه خانه بجنورد & هار امتر \\
\hline- & $r \Lambda \cdot<$ & $r \Lambda \cdot-\mid r$. & $V \cdot-14 \cdot$ & $v \cdot>$ & TRI & $\mathrm{Cl}^{-}(\mathrm{mg} / \mathrm{L})$ \\
\hline$\Lambda \cdot<$ & $1 \cdot-9$. & G. $-\boldsymbol{r}$. & $r \cdot-r \cdot$ & $r \cdot>$ & $\varphi g / \pi \Delta$ & $\mathrm{Na}(\%)$ \\
\hline r...< & $r \cdots-r \ldots$ & $r \cdot \cdots-V \Delta \cdot$ & $R D \cdot-r \Delta \cdot$ & $r \Delta \cdot>$ & 194. & $\mathrm{EC}(\mu \mathrm{s} / \mathrm{cm})$ \\
\hline- & $r \varepsilon<$ & $r G-11$ & $1 \wedge-1$ & $1 \cdot>$ & r/A & SAR \\
\hline
\end{tabular}

يساب تصفيه خانه شهر كرمان كزارش كرده اند [If]

\section{نوترينت ها (نيتروزن و فسفر)}

يكى از جنبههاى مهم در كاربرد مجدد يساب فاضلاب،

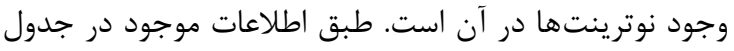

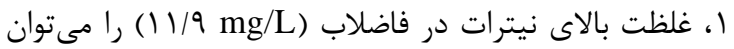

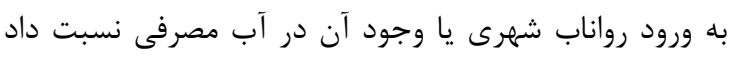

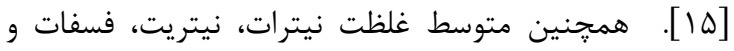

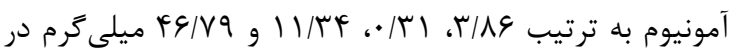

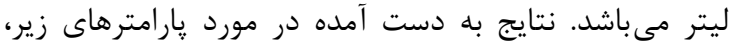

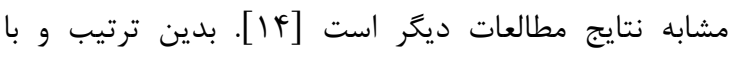

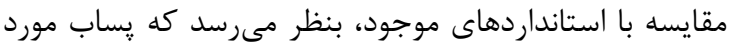

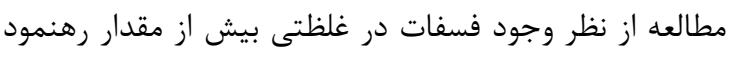

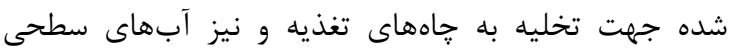

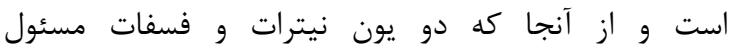

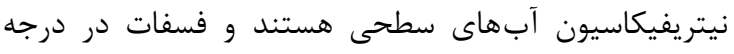

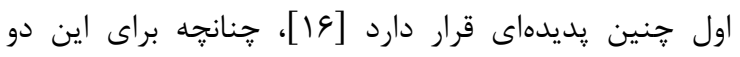

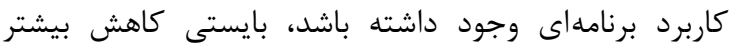

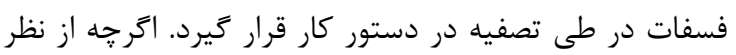

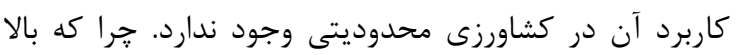

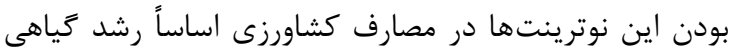

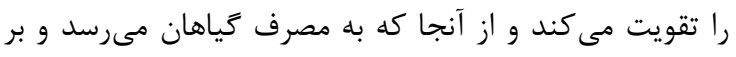

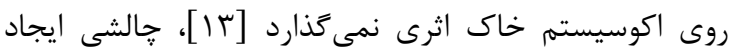

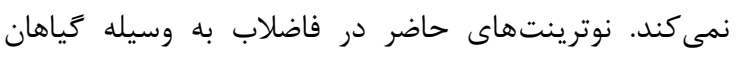

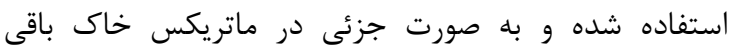
مقىماند و بر اكوسيستم خاك تاثير منفى ندارد. خوشبخت دئانه

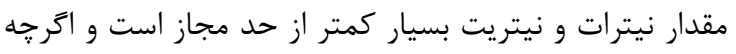

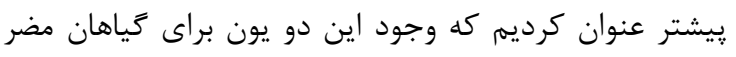

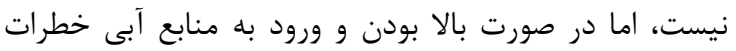

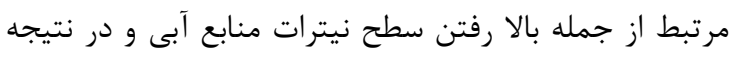

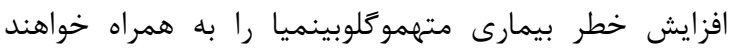

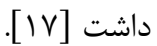

اكسيزن خواهى شيميا يي و بيولوزيكى

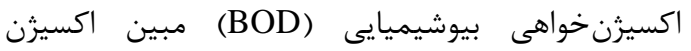

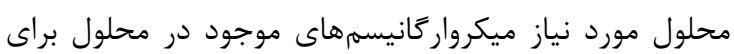

استفاده مجدد از فاضلاب شامل كاربرد مستقيم فاضلاب تصفيه شده براى آبيارى زمينهاى كشاورزى، آبيارى شهرى آنادي،

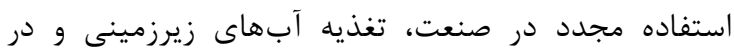
بعضى موارد تميزسازى خيابانها، شستشوى ماشين و ودرد درد

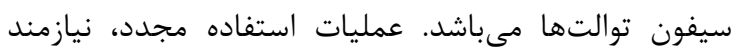
ميزانى از تصفيه است كه كسترهاى از تصفيه ثانويه تا تصفيه

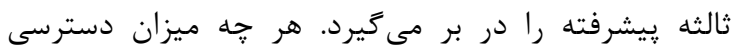

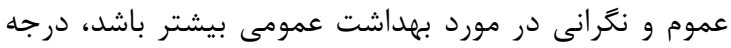

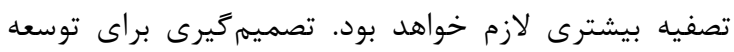

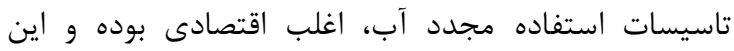

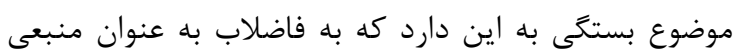

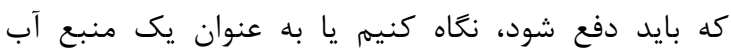

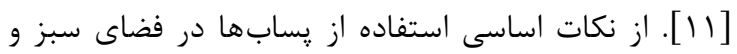

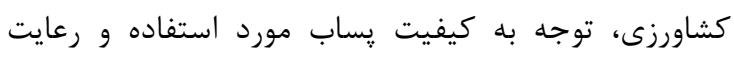

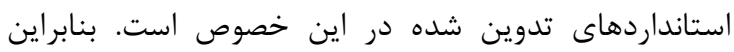
بهتر است استفاده مجدد، به صورت برنامهانه ريزى شرئ شده و

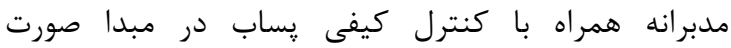

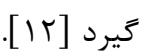

\section{فعاليت يون هيدروزن و قليائيت}

pH

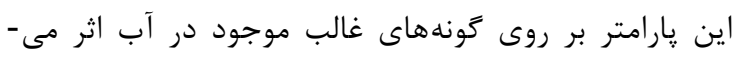

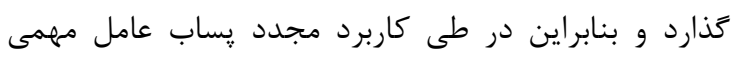

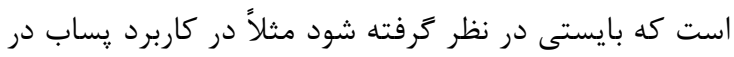

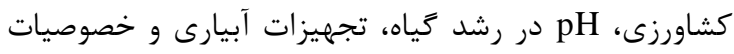

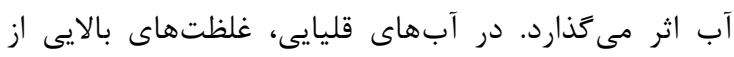

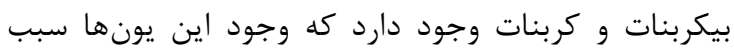

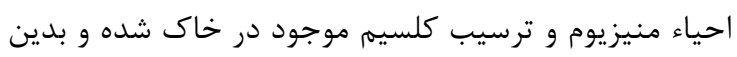

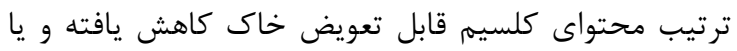

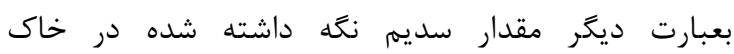

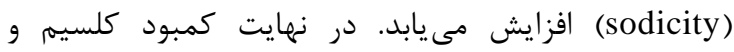

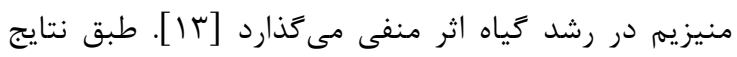

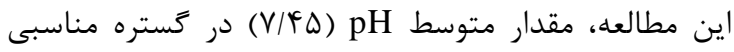

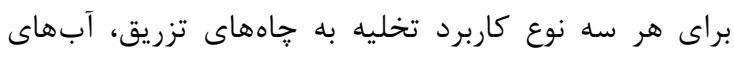

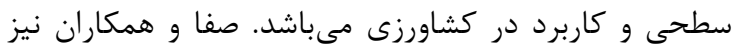

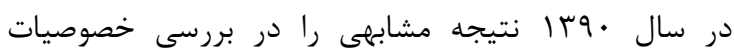


كيفيت آب كشاورزى است. نمكهاى محلول در آب با شورى خاك در ارتباط هستند و بر اين اساس؛ رشد ردئ دياه،

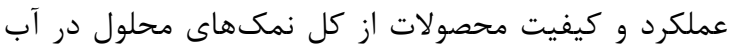

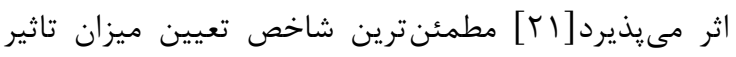
آب آبيارى بر افزايش سديم تبادلى خاك، يارامتر نسبت

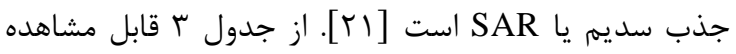

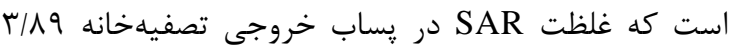

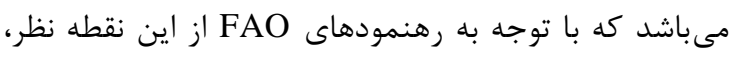

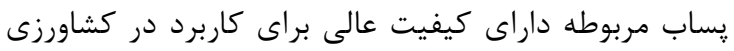

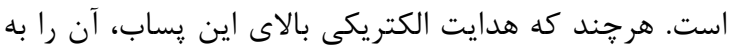

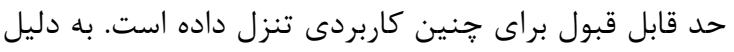

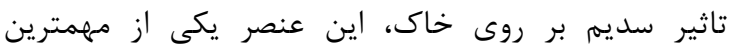

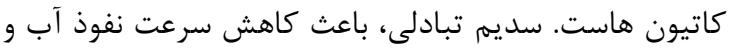

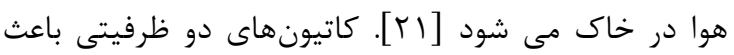

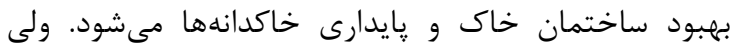

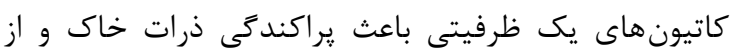

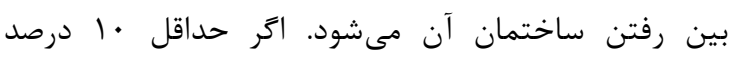

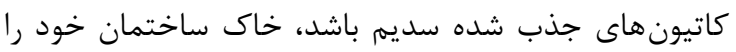

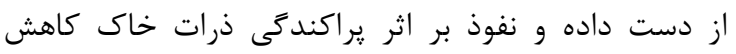

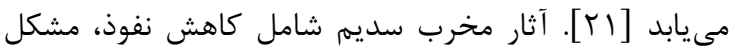

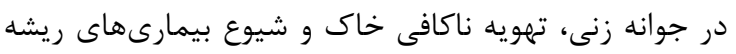

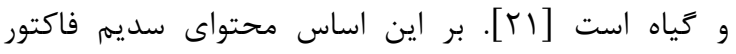

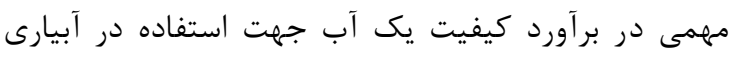

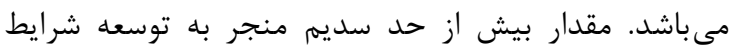

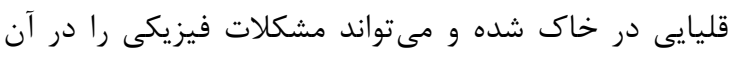

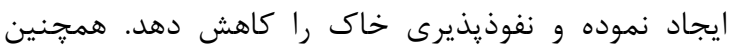

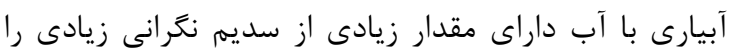

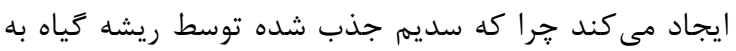

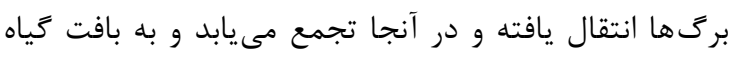

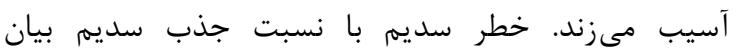

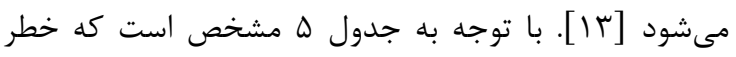
سديم براى خاى در صورت كاربرد يساب تصفيه خانه مورد مطالعه اندك مى باشد.

نكته مهرم ديخر در جدول f آنست كه با توجه به غلظت

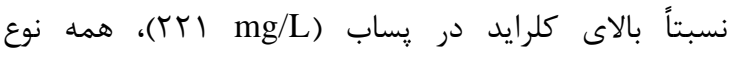
محصولات كشاورزى را نمى توان با جنين آبى آبيارى نمود جراب آنسا

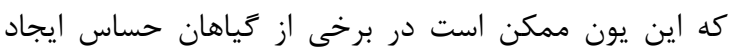

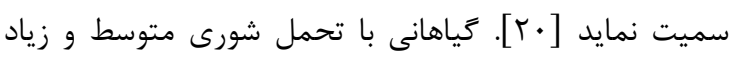

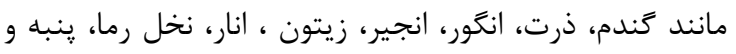

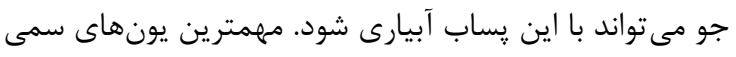

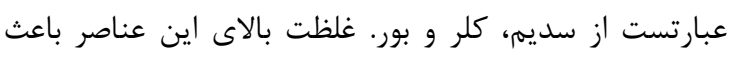
اختلال در عملكرد، كاهش عملكرد محصول، تغيير شكل
شكستن مواد آلى نمونه در دما و مدت زمان مشخصى است.

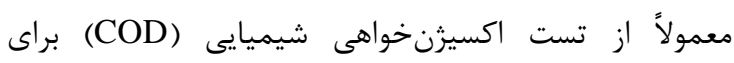

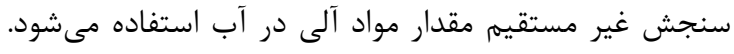

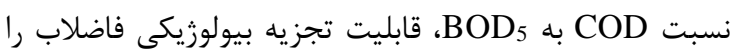

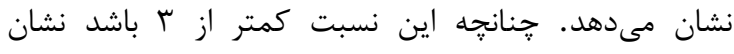

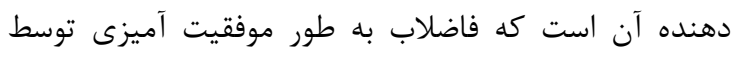

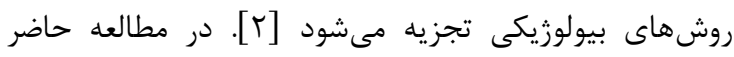

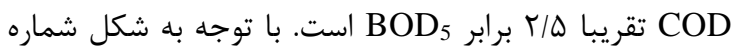

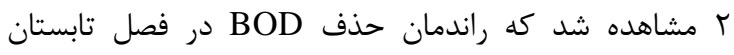
بيش از فصول ديگر سال بود كه مىتواند به دليل بالاتر بودن

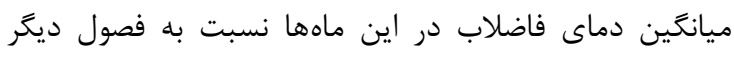

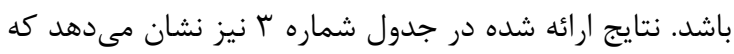

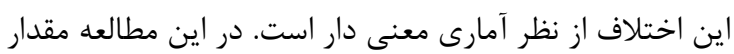
BOD

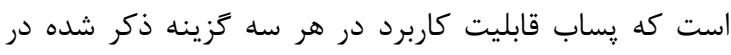

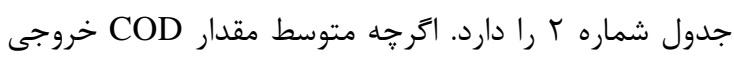

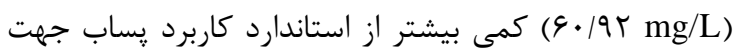

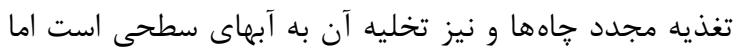

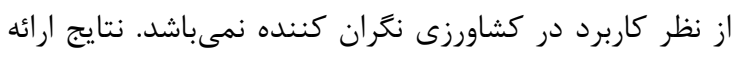

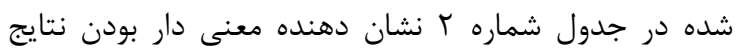

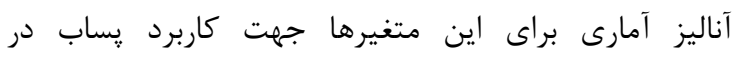

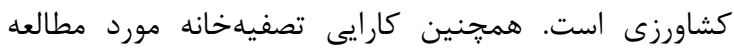
نسبت به يساب خروجى از تصفيهخانه كرمان كه با فرجنين كايند

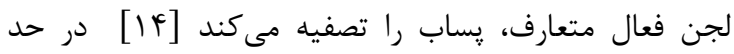

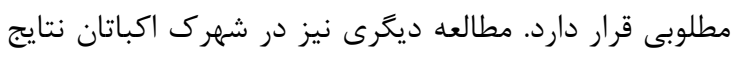
مشابهى در حذف اين متغيرها از فاضلاب نشان داد [111]. لازم به ذكر است كه مىتوان با اتخاذ تدابيرى مقدار خروجى را به استانداردهاى دو گزينه مذكور نيز رسات رسانيد.

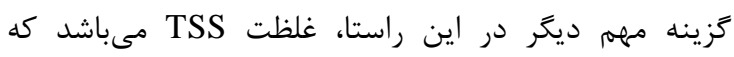

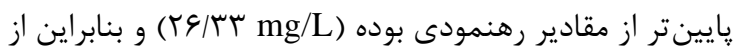

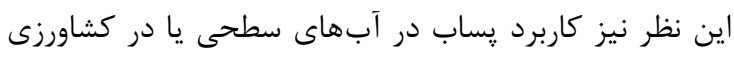
نغران كننده نمى باشد.

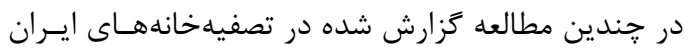

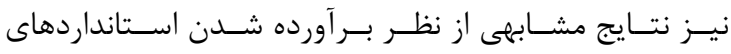

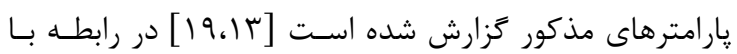

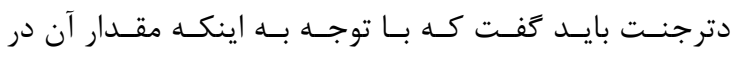

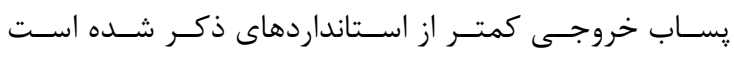

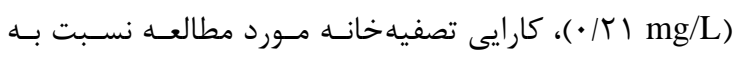

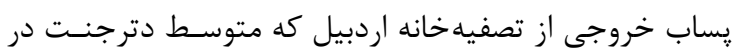

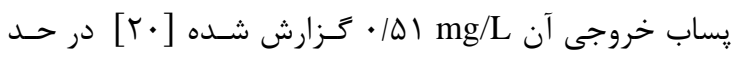
مطلوبى قرار دارد.

خطر شورى (TDS و

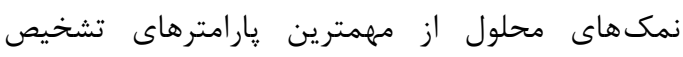


نتيجه تيرى

با توجه به نتايج به دست آمده از اين مطالعه مشخص

كرديد كه سيستم تصفيه فاضلاب بجنورد از نقطه نظر راندمان

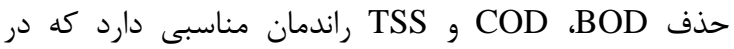

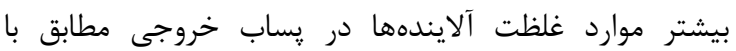
استانداردهاى مربوط به كاربرد آن در كشاورزى مى باشد. نتايج دئن

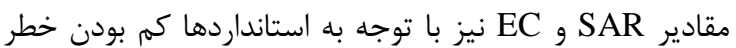
سديم براى خاى (در مصرف كشاورزى) را تاييد مى كند اما بالا

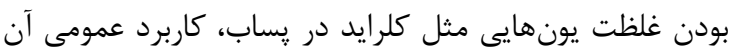

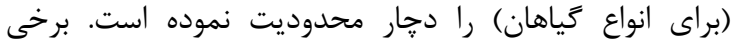

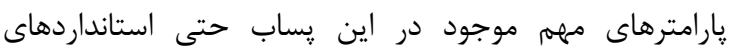

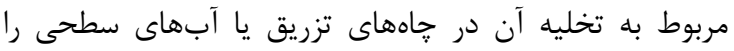
برآورده مى كند. تشكر و قلرواذى بدين وسيله از حمايتهاى شركت آب و فاضلاب شهرستان

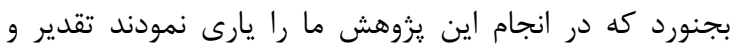

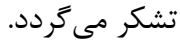

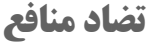
اين مطالعه براى نويسنده هيج گَونه تضاد منافعى نداشته

\section{REFERENCES}

1. Hammer MJ. Water and wastewater technology. 1986.

2. Moghadam FM, Mahdavi M, Ebrahimi A, Tashauoei HR, Mahvi AH. Feasibility study of wastewater reuse for irrigation in Isfahan, Iran. Middle East J Sci Res. 2015:23:2366-73.

3. Bagheri Ardebilian P, Sadeghi H, Nabaii A, Bagheri Ardebilian M. Assessment of Wastewater Treatment Plant Efficiency: a Case Study in Zanjan. Journal of Health. 2010;1(3):67-75.

4. Nasseri S, Sadeghi T, Vaezi F, Naddafi K. Evaluation Of The Possible Options For Reuse Of Ardebil Wastewater Treatment Plant Effluent. 2008.

5. Allen RG, Pereira LS, Raes D, Smith M. FAO Irrigation and drainage paper No. 56. Rome: Food and Agriculture Organization of the United Nations. 1998;56:97-156.

6. Huertas E, Salgot M, Hollender J, Weber S, Dott W, Khan $\mathrm{S}$, et al. Key objectives for water reuse concepts. Desalination. 2008;218(1-3):120-31. doi: 10.1016/j.desal. 2006.09.032

7. Cirelli G, Consoli S, Licciardello F, Aiello R, Giuffrida F, Leonardi C. Treated municipal wastewater reuse in vegetable production. Agricultural Water Management. 2012;104:163-70. doi: 10.1016/j.agwat.2011.12.011

8. Nasseri S, Sadeghi T, Vaezi F, Naddafi K. Quality of Ardabil wastewater treatment plant effluent for reuse in agriculture. 2012.

9. http://www.thesustainabilitycouncil.org/resources/the-koppenclimate-classification-system/

10. Federation WE, Association A. Standard methods for the examination of water and wastewater. American Public Health Association (APHA): Washington, DC, USA. 2005.

11. Pedrero F, Kalavrouziotis I, Alarcón JJ, Koukoulakis P,

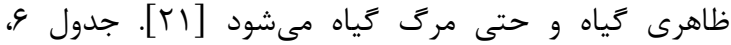
طبقهبندى آب جهت آبيارى از نظر وجود كلرياه وايد راه نشان

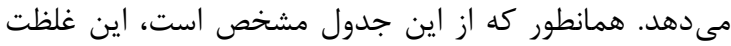

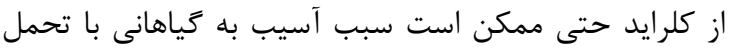
متوسط گردد.

جدول ه: مقايسه مقدار SAR بساب تصفيهخانه بجنورد با مقادير

[r] استاندارد [r]

\begin{tabular}{|c|c|}
\hline مقادير SAR & خطر سديم براى خاى \\
\hline $1 \cdot \ldots$ & كم \\
\hline $1 \wedge-1$. & متوسط \\
\hline$r G-11$ & زياد \\
\hline$>r \varepsilon$ & بسيار زياد \\
\hline ऍ/^৭ & يساب تصفيهخانه بجنورد \\
\hline
\end{tabular}

جدول و: طبقه بندى آب جهت آبيارى از نظر غلظت كلر ايد آن [؟]

\begin{tabular}{|c|c|}
\hline اثر بر محصولات كشاورزى & كلرايد (mg/L) \\
\hline معمولاً براى انواع كياهان ايمن است. & $v \cdot>$ \\
\hline به كَياهان حساس آسيب مىزند. & $\mid f \cdot-V \cdot$ \\
\hline به كياهان نيمه حساس آسيب مىزند. & $r \Delta \cdot-|f|$ \\
\hline مى تواند سبب مشكلات جدى شود. & $>r \Delta \cdot$ \\
\hline
\end{tabular}

Asano T. Use of treated municipal wastewater in irrigated agriculture - Review of some practices in Spain and Greece. Agricultural Water Management. 2010;97(9):1233-41. doi: 10.1016/j.agwat.2010.03.003

12. Agrafioti E, Diamadopoulos E. A strategic plan for reuse of treated municipal wastewater for crop irrigation on the Island of Crete. Agricultural Water Management. 2012;105:57-64. Doi: 10.1016/j.agwat.2012.01.002

13. Mariolakos I. Water resources management in the framework of sustainable development. Desalination. 2007;213(1-3):147-51. doi: 10.1016/j.desal.2006. 05.062

14. Safa F, Malakutian M, kord mostafa pour f. Feasibility of using Kerman wastewater treatment plant in agriculture. Water Research in Agriculture. 2014;28(1)

15. Vega E, Lesikar B, Pillai SD. Transport and survival of bacterial and viral tracers through submerged-flow constructed wetland and sand-filter system. Bioresource technology. 2003;89(1):49-56. doi: 10.1016/S09608524(03)00029-4

16. Chen Z, Ngo HH, Guo W, Lim R, Wang XC, O'Halloran K, et al. A comprehensive framework for the assessment of new end uses in recycled water schemes. Science of the Total Environment. 2014;470:44-52. Doi: 10.1016/j. scitotenv.2013.09.061

17. Prazeres AR, Rivas J, Almeida MA, Patanita M, Dôres J, Carvalho F. Agricultural reuse of cheese whey wastewater treated by $\mathrm{NaOH}$ precipitation for tomato production under several saline conditions and sludge management. Agricultural Water Management. 2016;167:62-74. doi: 10.1016/j.agwat.2015.12.025

18. Torabian A, Motalebi M. Management plan for reuse of refined effluent (case study: Ekbatan Town). Ecology. $2003 ; 29(32)$ 
19. Kalavrouziotis IK, Apostolopoulos CA. An integrated environmental plan for the reuse of treated wastewater effluents from WWTP in urban areas. Building and Environment. 2007;42(4):1862-8. doi: 10.1016/j.buildenv. 2006.07.016

20. Mehravaran B, Ansary H, Beheshti A, Esmaili K. Investigate the Feasibility of Using Wastewater Purication in Irrigation Due to Its Environmental Impacts (The effluent treatment plants parkandabad Mashhad). iranian journal of irrigation and drainage. 2015;3:440-7.

21. Rutkowski T, Raschid-Sally L, Buechler S. Wastewater irrigation in the developing world - two case studies from the Kathmandu Valley in Nepal. Agricultural Water Management. 2007;88(1):83-91. doi: 10.1016/j.agwat. 2006.08.012 